\title{
Tratamento químico e biológico em volumosos para ruminantes
}

\author{
${\underline{B r a u l i o ~ C r i s a n t o ~ C a r v a l h o ~ d a ~} \mathrm{Cruz}^{1}}^{1}$ \& Denise Araújo da Silva ${ }^{1}$ \\ ${ }^{1}$ Instituto Federal de Educação, Ciência e Tecnologia de Roraima - IFRR. Campus Novo Paraíso, BR-174, Km - \\ 512 - Vila Novo Paraíso - Caracaraí - RR / CEP: 69.365-000. - braulio.cruz@ifrr.edu.br
}

\begin{abstract}
RESUMO. O Brasil, por ser um dos principais produtores agrícolas mundiais, gera anualmente uma grande variedade e quantidade de resíduos agroindustriais. Estes resíduos podem assumir importância considerável na alimentação de ruminantes, principalmente, em períodos, nos quais a escassez de forragens torna-se o fator preponderante que limita a produtividade desses animais. A finalidade de estudo desses resíduos agroindustriais destina-se não somente a busca por sanar a escassez de alimentos para ruminantes durante a época de redução da produtividade das gramíneas tropicais, mas também um aumento com a preocupação com o meio ambiente. Uma parcela dos resíduos produzidos hoje como bagaço de cana-de-açúcar, resíduos de pós-colheita de sementes, resíduos de despolpamento de frutos e palhas, são de baixa qualidade, pois apresentam alto conteúdo de parede celular (valores acima de 60\%) e de fibra em detergente ácido (FDA) acima de 40\%, e baixos teores de proteína bruta (PB) (abaixo de $6,0 \%$ ), de minerais e de vitaminas, sendo a digestibilidade da matéria seca (MS) baixa (40 a 50\%) o que resulta em baixos níveis de consumo.
\end{abstract}

Palavras chave: Amonização, forragem, nutrição, ruminantes

\section{Chemical and Biological treatment in bulky for ruminants}

\begin{abstract}
Brazil, for being one of the major agricultural producers, annually generates a large variety and quantity of agro-industrial waste. These residues can assume considerable importance in the feeding of ruminants, especially during periods in which the shortage of fodder becomes the dominant factor limiting the productivity of these animals. The purpose of studying these agroindustrial waste intended not only the search for remedy the shortage of ruminant feed during the time of reduced productivity of tropical grasses, but also an increase in concern about the environment. A portion of the waste produced today as bagasse from sugarcane, post-harvest seed waste pulping waste fruit and straw, they are of poor quality, since they have high cell wall content (values above 60\%) and acid detergent fiber (ADF) above 40\%, and lower crude protein (CP) (below 6.0\%), minerals and vitamins, and the digestibility of dry matter (DM) Low (40 $50 \%$ ), which results in low levels of consumption.
\end{abstract}

Keywords: Ammonization, forage, nutrition, ruminants

\section{Introdução}

Forragens, em geral, apresentam estrutura complexa em sua parede celular, composta, principalmente, das frações de celulose, hemicelulose e lignina (Garcia \& Pires, 1998). A associação da lignina com as outras duas frações é responsável pela baixa digestibilidade de muitas forragens.

Rosa \& Fadel (2001), em revisão, abordam sobre as tendências e perspectivas da produção de bovinos de corte. Os autores descreveram que a terminação de animais em confinamentos deveria aumentar, o que pode ser confirmado nos dias atuais. Por considerarem a alimentação o item de maior importância, por representar maior parcela de custo, relata também que ocorrerá uma polarização de confinamentos ao redor de usinas e de destilarias de açúcar e álcool, face aos produtos produzidos por essa cadeia agroindustrial, como o bagaço e as pontas de cana-de-açúcar. As indústrias que processam outros produtos agrícolas (conserva de alimentos, limpeza de grãos como soja, milho, sementes 
etc.) também têm a capacidade de provocar a concentração de áreas de confinamento de bovinos ao seu redor.

\section{Tratamento químico}

A quantidade de resíduos de pós-colheita de sementes de forrageiras tropicais no Brasil, é grande, estima-se que anualmente sejam descartados 2,8 milhões de toneladas de matéria seca (Souza \& Silveira, 2006). A queima tem sido a alternativa preferida de eliminação desse resíduo, pois é barata, rápida e eficiente, além de controlar ervas daninhas, doenças e pragas, porém essa prática contribui para poluição do ar pela liberação de fumaça, gases e partículas (Andrade, 2006).

O alongamento de caule, resultado do florescimento das plantas implica na redução da relação folha/caule, resultando em forragem de valor nutritivo reduzido (Reis et al., 2001). Segundo esses autores os fenos produzidos com esse material com alto teor de fibra, muito lignificado e com baixo teor de proteína podem ser melhorados com aplicação de produtos químicos. Diversas pesquisas têm indicado que o tratamento de volumosos de baixo valor nutritivo, utilizando fontes de amônia, pode melhorar a qualidade desses produtos, elevando significativamente seu valor nutritivo, consumo e consequentemente, aproveitamento pelos animais, por promover alterações acentuadas nos componentes das frações fibrosas e compostos nitrogenados (Pereira et al., 1993; et al., 1998a; Reis et al., 2001; Fernandes et al., 2002; Pires et al., 2004; Zanine et al., 2007).

Em estudo realizado por Roth et al. (2009) concluiu-se que as doses de amônia de 2 e $3 \%$ em feno de Brachiaria brizantha cv. Marandu provenientes de resíduos de colheita de sementes foram eficientes em melhorar o valor nutritivo dessa forragem. Nesse mesmo estudo, foi elucidada a necessidade de ensaios com desempenho animal para definir a viabilidade econômica da dose a ser utilizada.

Diversos recursos têm sido testados visando melhorar o aproveitamento de forragens de baixa qualidade, como tratamentos físicos, químicos ou biológicos, suplementação ou combinação de dois ou mais destes (Rosa et al., 1998). Uma alternativa viável para melhorar o valor nutritivo desses volumosos é o tratamento dos fenos com produtos químicos, sendo mais utilizados os hidróxidos de sódio, potássio, cálcio e amônio, a amônia anidra e a ureia como fonte de amônia (Sundstol \& Coxworth, 1984; Berger et al., 1994; Reis et al., 2001). Segundo Rosa \& Fadel (2001) dentre os tratamentos químicos avaliados, principalmente com palhas ou resíduos de culturas e, mais recentemente, com fenos, destacam-se o uso da amônia anidra $\left(\mathrm{NH}_{3}\right)$ ou da ureia, processo denominado de amonização.

Em revisão Rodrigues \& Souza (2006) descrevem sobre vantagens e desvantagens na escolha do produto químico que se deseja utilizar na amonização de volumosos. O hidróxido de sódio é apontado como o mais eficiente, porém de difícil aplicação, alto custo além de proporcionar riscos de contaminação ambiental, como alternativa a esse produto tem-se $\mathrm{o}$ hidróxido de cálcio, porém com menor eficiência. Do mesmo modo os autores classificam a amônia, e colocam a ureia como alternativa por apresentar eficiência semelhante, menor custo, aplicação facilitada e não prejudicar a saúde.

A amônia anidra é o nome químico dado ao composto que apresenta um átomo de nitrogênio e três de hidrogênio $\left(\mathrm{NH}_{3}\right)$. Possui teor elevado de nitrogênio (82\%) e, normalmente, é encontrada no estado líquido sob baixas temperaturas ou pressões relativamente altas. A ureia $\left(\mathrm{NH}_{2} \mathrm{CONH}_{2}\right)$, que, por sua vez, possui, em média, $44 \%$ de nitrogênio, é encontrada na forma sólida e necessita de umidade e presença da enzima urease para que possa produzir $2 \mathrm{NH}_{3}+$ $\mathrm{CO}_{2}$, para cada molécula de ureia (Pires et al., 2004).

A utilização desses compostos alcalinos em volumosos tem efeito na parede vegetal chamado de ureólise. De acordo com Rosa \& Fadel (2001) a ureólise é uma reação enzimática que requer a presença da enzima "urease" no meio. A urease é praticamente ausente nas palhas ou material morto, como por exemplo, os capins secos. De acordo com Willians et al. (1984), a urease produzida pelas bactérias "ureolíticas", durante o tratamento de resíduos, tais como as palhadas, é suficiente, pelo menos em determinadas condições onde a umidade não é limitante. Somente em casos específicos de forragens muito secas, e que não possam ser umedecidas, a adição de urease seria necessária. A umidade e a temperatura, e suas interações, devem favorecer a atividade da bactéria e de sua enzima.

$\mathrm{O}$ tratamento de forragens ricas em lignina e celulose com amônia anidra, segundo os mesmos autores, teve início na primeira década do século 
passado. Na década de setenta, os trabalhos foram bastante desenvolvidos na Europa e, nesta mesma década, foram iniciados nos Estados Unidos. No Brasil, os trabalhos de pesquisa tiveram início em 1984 (Rosa \& Fadel, 2001).

De acordo com Reis \& Rodrigues (1993) três reações podem ocorrer com a adição de amônia em volumosos, ressaltando que os mesmos processos podem ocorrer com ureia após transformação em amônia.

A primeira reação, definida pelos autores como a de maior importância, é a reação de amoniólise, onde ocorre reação entre a amônia e um éster, produzindo uma amida. Essas ligações do tipo ésteres podem ser encontradas entre a hemicelulose ou a lignina com grupos de carboidratos estruturais.

A reação de amoniólise pode ser esquematizada (Roth, 2008):

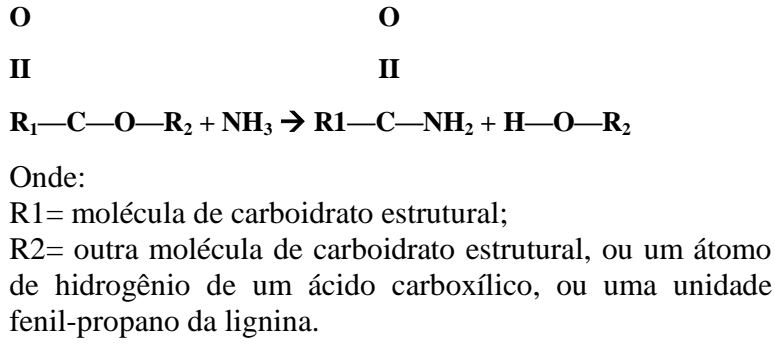
de hidrogênio de um ácido carboxílico, ou uma unidade fenil-propano da lignina.

A segunda equação baseia-se na característica da amônia em apresentar alta afinidade com a água, resultando na formação de uma base fraca, o hidróxido de amônio $\left(\mathrm{NH}_{4} \mathrm{OH}\right)$, durante o tratamento de forragens úmidas com esse composto.

A reação de formação do hidróxido de amônio pode ser esquematizada:

\section{$\mathrm{NH}_{3}+\mathrm{H}_{2} \mathrm{O} \rightarrow \mathrm{NH}_{4} \mathrm{OH}$}

A terceira reação, segundo os autores seria a hidrólise alcalina das ligações tipo éster, que ocorre na sequencia do processo da segunda reação, onde a base fraca, $\mathrm{NH}_{4} \mathrm{OH}$, proporciona hidrólise alcalina resultante da reação do hidróxido de amônio com as ligações ésteres entre os carboidratos estruturais da forragem.

A reação de hidrólise alcalina das ligações tipo éster pode ser esquematizada:

$$
\begin{array}{lc}
\mathrm{O} & \mathrm{O} \\
\mathrm{II} & \mathrm{II} \\
\mathrm{R}_{1}-\mathrm{C}-\mathrm{O}-\mathrm{R}_{2}+\mathrm{NH} 4 \mathrm{OH} \rightarrow \mathrm{R} 1-\mathrm{C}-\mathrm{O}+\mathrm{NH}_{4}{ }^{++} \mathrm{H}-\mathrm{O}-\mathrm{R}_{2}
\end{array}
$$

Onde:

$\mathrm{R} 1=$ molécula de carboidrato estrutural;

R2= outra molécula de carboidrato estrutural, ou um átomo de hidrogênio de um ácido carboxílico, ou uma unidade fenil-propano da lignina.

A análise dos dados obtidos por Reis et al. (2001) com amonização de fenos de Brachiaria decumbens e análise dos resultados relatados por Bertipaglia et al. (2005) com amonização de fenos de Brachiaria brizantha cv. Marandu sugerem que a atividade ureática dos fenos dessas plantas colhidas no estádio de pós-florescimento é suficiente para desdobrar a ureia aplicada, desde que os conteúdos de umidade não limitem a atividade da enzima. Os autores relatam a necessidade de mais estudos a fim de definir essa umidade que ficaria em torno de 20 a $30 \%$.

Por sua vez, Buetiner et al. (1982) avaliando o efeito da amonização sobre o feno de Festuca arundinacea Schreb.,) verificaram a ação da amônia sobre as ligações do tipo ésteres com a consequente redução na absorbância para os comprimentos de ondas relativos às ligações do tipo ésteres e aumento nas ligações amidas. Os pesquisadores salientaram que as modificações nas propriedades de absorbância no feno tratado resultaram da quebra de ligações do tipo ésteres por meio de uma reação "amoniólise", com a consequente formação de amidas.

Segundo Rosa \& Fadel (2001) a alta afinidade da amônia com a água promove expansão da parede celular e ruptura de componentes dos tecidos de forragens amonizadas, que podem ser constatados por meio de estudos de microscopia eletrônica.

Segundo Reis \& Rodrigues (1993), além desse efeito sobre a fibra, o qual aumenta a disponibilidade de carboidratos prontamente fermentescíveis para os microrganismos do rúmen, a amonização eleva o conteúdo de nitrogênio não protéico dos volumosos de baixa qualidade. O resultado é um aumento significativo (8 a 12\%) na digestibilidade da forragem tratada.

Além de melhorar o valor nutritivo a amonização pode ser utilizada no controle de microrganismos indesejáveis ao processo de fenação ou ensilagem. $\mathrm{Na}$ literatura são apresentados relatos da presença de fungos em fenos, principalmente em função do armazenamento com umidade superior a $20 \%$, o que implica em deterioração do volumoso 
(Freitas et al., 2002) podendo ocasionar problemas sanitários nos rebanhos e até prejuízos à saúde humana.

O tratamento com amônia anidra ou ureia promove alterações acentuadas na composição química do volumoso, principalmente nos componentes da fração fibrosa e nos compostos nitrogenados (Pereira et al., 1993; Rosa et al., 1998a; Reis et al., 2001). Uma das principais alterações na composição química da fração fibrosa de volumosos tratados com amônia é a solubilização da hemicelulose, resultando em diminuição no conteúdo de FDN (5 a 12\%). Estudos que pesquisaram os efeitos da amonização sobre os conteúdos de FDA, celulose e lignina não são consistentes (Sundstol \& Coxworth, 1984).

Pires et al. (2003) em revisão sobre amonização, descreve que essa técnica tem sido utilizada com o intuito de conservar forragens com alto teor de umidade, como silagens, e também para a melhoria do valor nutritivo de volumosos em geral por meio do fornecimento de nitrogênio não protéico, por redução de na fração da fibra em detergente neutro (FDN) e pelo aumento na digestibilidade do material tratado. $\mathrm{O}$ mesmo autor relata que a dose de nitrogênio aplicada está em torno de 1,0 a 1,5\% de amônia anidra e de 3,0 a 5,0\% de ureia, com base na matéria seca, quando o objetivo for conservação, e de 2,0 a 4,0\% de amônia anidra e de 7,0 a $8,0 \%$ de ureia quando o objetivo for a melhoria na qualidade do material com baixa digestibilidade (Pires et al, 2003).

Pires et al. (2004) relata que nos tratamentos de bagaço de cana-de-açúcar onde se utilizou $\mathrm{NH} 3$ (4,0\% na MS), teve-se aumento da proteína bruta $(\mathrm{PB})$ de $1,8 \%$ no bagaço sem tratamento para $16,9 \%$ no bagaço tratado com $\mathrm{NH}_{3}$ e da DIVMS de $32,1 \%$ no bagaço sem tratamento para $59,8 \%$ no bagaço tratado com $\mathrm{NH} 3$, redução da FDN de $94,7 \%$ no bagaço sem tratamento para $75,8 \%$ no bagaço tratado com $\mathrm{NH}_{3}$ e da hemicelulose de $33,1 \%$ no bagaço sem tratamento para $19,4 \%$ no bagaço tratado com $\mathrm{NH} 3$, enquanto para FDA e celulose menores variações nos valores. Com base nestes resultados, também se pode verificar a eficiência da $\mathrm{NH}_{3}$ no tratamento do bagaço de cana-deaçúcar.

Rosa et al. (1998) estudando amonização de fenos de Brachiaria decumbens com dois níveis de amônia (2,0 ou 3,0\% na MS) e dois níveis de ureia $(3,6$ ou $5,4 \%$ na MS) observaram modificações acentuadas nas frações nitrogenadas, destacando-se aumento no conteúdo de nitrogênio não protéico em relação ao nitrogênio total fixado nos fenos tratados com amônia e ureia, independente da dose adicionada com valores oscilando entre 73,6 a 81,2\%.

Trabalho realizado por Fernandes et al. (2002) apresentou resultado onde a amonização utilizando $\mathrm{NH} 3$ (3,0\% na MS) ou ureia (5,0\% na MS) aumentou significativamente a digestibilidade in vitro da MS (DIVMS) dos fenos de Brachiaria decumbens em 12,1 e 6,64 unidades percentuais, respectivamente, elevando a DIVMS de $47,5 \%$ do feno não tratado para $59,6 \%$ no feno tratado com $\mathrm{NH}_{3}$ e $54,2 \%$ no feno tratado com ureia. De acordo com os autores o incremento observado na DIVMS provavelmente foi devido às modificações na composição química da fração fibrosa, como a diminuição no conteúdo de FDN e de hemicelulose o que certamente disponibilizou carboidratos prontamente digestíveis para os microrganismos do rúmen. Associado a estas modificações, o aumento de nitrogênio disponível propicia melhores condições de desenvolvimento para as bactérias do rúmen o que aumenta a digestibilidade da forragem. Nesse mesmo trabalho os valores de FDN e hemicelulose observados foram, respectivamente de 83,9 e $32,2 \%$ do feno não tratado, 79,4 e $31,3 \%$ no feno tratado com $\mathrm{NH}_{3}$ e 812,0 e $29,2 \%$ no feno tratado com ureia.

No trabalho de Reis et al. (2001) os autores observaram que a relação entre a fração de nitrogênio insolúvel em detergente ácido e o nitrogênio total (NIDA/NT) diminuiu acentuadamente em resposta às aplicações de $\mathrm{NH} 3$ e ureia. Foram observados valores médios da relação NIDA/NT de 47,3; 20,6; e 15,9, respectivamente, para os fenos não tratados, tratados com amônia anidra ou com ureia. A observação destes dados evidencia que a adição de NNP da amônia anidra ou da ureia promoveu diluição do conteúdo de NIDA, aumentando a quantidade de $\mathrm{N}$ disponível para os microrganismos do rúmen, ou seja, NT menos a fração de NIDA (Sniffen et al., 1992).

Pires et al. (2003) utilizando o tratamento com amônia (3\%) em silagens de sorgo observou aumento no consumo de MS por novilhas de corte $320 \mathrm{~g}$ de $\mathrm{MS} /$ dia em relação às silagens controle $(\mathrm{P}<0,05)$, pois nesse estudo os autores 
observaram redução de aproximadamente 5 unidades percentuais no conteúdo de FDN.

Fernandes et al. (2002) avaliando a qualidade de feno de Brachiaria decumbens a monizado fornecido a novilhos zebu, com peso médio de $230 \mathrm{~kg}$, observaram diferença nos valores de consumo de MS em relação ao peso dos animais (CMS/PV), os animais alimentados com feno não tratado apresentaram consumo de 2,0\% PV, nos que recebiam feno tratado com $\mathrm{NH} 3$ observou-se consumo de $2,2 \%$ do PV e na dieta com feno tratado com ureia foi de $1,9 \% \mathrm{PV}$, evidenciando superioridade do feno tratado com $\mathrm{NH}_{3}$, segundo o autor a diferença de 12,8\%, atribuí-se o aumento do consumo a maior digestibilidade, principalmente da fração fibrosa.

Nos estudos desenvolvidos para se avaliar o valor nutritivo de volumosos amonizados, a inclusão de fontes de energia e, ou, proteína tem proporcionado aumentos substanciais na eficiência de utilização da forragem tratada (Rosa \& Fadel, 2001).

Pires et al. (2004) com amonização de bagaço de cana para alimentação de novilhas cruzadas (Indubrasil x Holandês) com peso médio de 230 $\mathrm{kg}$; pode ser observado valores de CMS/PV significativamente maiores nos tratamentos com $\mathrm{NH}_{3}(2,46 \%)$ e no tratamento com $\mathrm{Na}_{2} \mathrm{~S}$ e $\mathrm{NH}_{3}$ $(2,42 \%)$ e menores nos tratamentos não amonizado $(1,92 \%)$ e apenas com Na2S $(2,06 \%)$. $\mathrm{O}$ autor ainda descreve um ganho médio diário de peso em $\mathrm{kg}$ como sendo, $1,03 \mathrm{~kg}, 1,00 \mathrm{~kg}, 0,70$ $\mathrm{kg}$ e $0,68 \mathrm{~kg}$, respectivamente nos tratamentos de bagaço de cana com NH3, Na2S e NH3, bagaço não amonizado e $\mathrm{Na}_{2} \mathrm{~S}$.

Segundo Pinheiro (2009), a dieta com o resíduo da produção de sementes de Brachiaria brizantha amonizado não promove melhora no desempenho dos animais e também não altera as medidas morfológicas realizadas in vivo. Neiva et al. (1998), que, em avaliação do desempenho de bovinos que receberam diferentes dietas, concluíram que a amonização do volumoso não melhorou o ganho de peso dos animais. FurushoGarcia et al. (2000) não encontraram diferença no ganho de peso de cordeiros alimentados com volumoso tratado com $4 \%$ de ureia $+1 \%$ de grão de soja moído $(0,19 \mathrm{~kg} /$ dia $)$ em relação ao volumoso não tratado $(0,19 \mathrm{~kg} / \mathrm{dia})$.

Na suplementação de ruminantes, alimentados com volumosos de baixa qualidade, o consumo total de matéria orgânica digestível depende da adequada relação entre a proteína degradável no rúmen e a matéria orgânica digestível, presentes na dieta do animal, a otimização dessa relação permite aumentar o consumo e a digestibilidade, em decorrência de alterações do ambiente ruminal, que resultam em melhor desempenho produtivo e reprodutivo dos animais, sendo que o aumento do consumo pode estar associado ao suprimento de $\mathrm{N}$, em quantidades adequadas à manutenção da atividade microbiana Dessa forma, em condições onde são utilizadas forragens de baixa qualidade, o primeiro fator nutricional limitante do desempenho animal é a disponibilidade de energia e, para os microrganismos ruminais, a disponibilidade de proteína e minerais. Sendo, portanto, de grande importância otimizar o ambiente ruminal, visando melhorar a utilização dos alimentos fibrosos. A otimização do ambiente ruminal depende, basicamente, do adequado fornecimento de substratos que permitam a manutenção e o crescimento da microbiota ruminal. No caso de alimentação volumosa de baixo valor nutritivo isto pode ser conseguido pela utilização de suplementos (Mallmann et al. 2006).

Nesse sentido, Roth (2008) relata que utilização de amônia no tratamento do feno de resíduo de pós-colheita de sementes mostra-se como alternativa eficiente na alimentação de bovinos confinados e proporcionou a produção de carcaças com acabamento desejável ao processo produtivo de carnes. A mesma autora afirma ainda que a suplementação de bovinos com farelo de algodão e feno colhido em estágio pós-florescimento amonizado, mostrou-se como alternativa melhor quando da utilização de fenos de baixo valor nutritivo sem qualquer tratamento químico.

Portanto, o desempenho dos animais alimentados com resíduos agroindustriais amonizados pode ser viável do ponto de vista técnico, desde que componha uma dieta nutricionalmente equilibrada. Há de se considerar que apenas o tratamento químico do volumoso não resolve todos os problemas inerentes ao mesmo. Necessita-se desta forma que essas estratégias estejam inseridas num planejamento alimentar onde se considera a disponibilidade da matéria-prima (volumoso) e dos produtos para a amonização a um baixo custo, bem como dos demais componentes necessários para compor a dieta (Roth, 2008). 
Como já discutido, os aditivos químicos são frequentemente adicionados aos volumosos com o intuito de conservar e/ou promover redução nos constituintes da fração fibrosa, tornando-os mais digestíveis, cita-se como principais aditivos utilizados o sulfeto de sódio, ureia, amônia anidra, hidróxido de sódio e óxido de cálcio. Para os aditivos ureia e amônia anidra, além dos benefícios observados na redução dos constituintes da parede celular, é evidenciado elevação dos teores de nitrogênio dos materiais tratados (Souza et al., 2001).

Segundo Carvalho (2008). Dietas contendo cana-de-açúcar tratada com até $2,25 \%$ de óxido de cálcio na alimentação de ovinos provocam aumento do consumo da maioria dos nutrientes, entretanto, diminui os coeficientes de digestibilidade da matéria seca, fibra em detergente neutro e o teor de nutrientes digestíveis totais. O mesmo autor ainda afirma que mesmo com as modestas reduções nos coeficientes de digestibilidade da matéria seca, fibra em detergente neutro e no teor de nutrientes digestíveis totais, a elevação do consumo de matéria seca e fibra em detergente neutro, os quais apresentaram acréscimos de $20 \%$, justifica o uso de óxido de cálcio no tratamento químico da cana-de-açúcar para alimentação de ovinos.

\section{Tratamento biológico}

Os microrganismos, como os fungos, são considerados fonte unicelular de elevado teor protéico, além de apresentarem rápido crescimento e possibilidade de cultivo em vários tipos de substratos, podendo substituir os produtos proteicos existentes, sendo inserido dessa forma na indústria de alimentação animal. Os preços dos suplementos protéicos aumentam de forma abusiva frequentemente, existindo um grande interesse pelo aproveitamento destes alimentos não convencionais no Brasil (Butolo, 2001).

Os fungos anaeróbios produzem uma grande variedade de enzimas e geralmente degradam um espectro maior de substratos quando comparados com as bactérias do rúmen (Selinger et al., 1996).

Quanto à composição química das leveduras, elas apresentam de $68 \%$ a $83 \%$ de água, além de substâncias nitrogenadas, carboidratos, lipídios, vitaminas, minerais, entre outros. Como qualquer forma de vida, as leveduras necessitam de fatores físicos e químicos importantes, indispensáveis para seu crescimento e reprodução. Alguns elementos são basicamente necessários, como água, fontes de carbono e nitrogênio, oxigênio e minerais (Tortora et al, 2002). A maioria das leveduras são organismos saprófitas, entretanto, existem espécies patogênicas.

A biomassa de leveduras pode ser utilizada tanto integralmente quanto apenas alguns de seus componentes. Para isso são empregadas diferentes técnicas com a finalidade de se obter o produto final desejado (Vilela et al., 2000). Destaca-se ainda, dentre os microrganismos, como produtores de proteínas, podendo ser utilizadas na nutrição humana, não apenas como fonte protéica como também devido a teores adequados de vitaminas do complexo B; apresenta em termos de digestibilidade e valor biológico, em torno de $87 \%$.

No ecossistema do rúmen, tem sido descrita a interação entre fungos anaeróbios e outros microrganismos. Sabe-se que interações ocorrem entre eles e bactérias metanogênicas, não metanogênicas e protozoários (Trinci et al., 1994; Joblin et al., 2002). Bauchop \& Mountfort (1981) demonstraram que culturas de Neocallimas tixfrontalis degradavam papel de filtro mais extensivamente na presença de metanógenos do que em sua ausência. Em relação às bactérias não metanogênicas, há uma variedade no rúmen e acredita-se que as interações com os fungos anaeróbios podem envolver competição, sinergismo ou simbiose. No que diz respeito à interação com os protozoários do rúmen, acredita-se que, na natureza, esta deva ser de caráter mais complementar do que competitiva (Trinci et al., 1994).

Os fungos anaeróbios no rúmen colonizam materiais de origem vegetal, incluindo, dentre outros, farelo de trigo, palha de arroz, milho, gramas e materiais altamente recalcitrantes, como a madeira (Akin et al., 1992; Trinci et al., 1994). Estes fungos degradam rapidamente tais materiais, sendo o açúcar fermentado, com a formação de formato, acetato, lactato, etanol, $\mathrm{CO}_{2}$ e $\mathrm{H}_{2}$ como produtos finais principais (Ljungdahl et al., 1999).

Os fungos anaeróbios produzem enzimas com grande capacidade para degradar a paredecelular de plantas. Tais enzimas incluem celulases, xilanases, mananases, pectinases, B-glucanases, b-glucosidases, acetil-xilanaesterases e esterases fenólicas (Borneman et al., 1989; Li et al., 1999). Algumas enzimas estão presentes de forma individual, enquanto outras são encontradas em 
um complexo de alta massa molecular. Estudos sobre este complexo indicam que os mesmos são similares aos celulossomas presentes em bactérias anaeróbias (Fnautti et al., 1995; Li et al., 1997). Esta consideração é sustentada pelo fato de que várias hidrolases possuem domínios de peptídeos repetidos (DPR) entre dois domínios catalíticos ou na região amino- ou carboxiterminal, apesar de tais domínios não apresentarem sequências homólogas às regiões duplicadas conservadas de proteínas catalíticas celulossomais. É importante ressaltar que estas regiões não são requeridas para catálise. Adicionalmente, foi também observado que um domínio de peptídeo repetido de uma xilanase produzida por uma espécie de Piromyces liga-se a outras proteínas presentes nos complexos de Neocallimastix e piromyces (Li et al., 1997).

Os fungos anaeróbios produzem enzimas celulolíticas e hemicelulolíticas na forma de um complexo multi proteico, assim como individualmente. Estas enzimas apresentam uma alta atividade específica, tendo, portanto, grande potencial para aplicação industrial. (Ximenes, 2003).

Rabelo (2011), em pesquisas realizadas objetivando o enriquecimento proteico de algaroba, observou que houve crescimento até 24 horas, onde as concentrações celulares iniciais

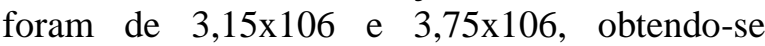

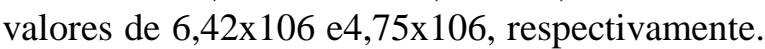
Após esse tempo, os valores da UFC/mL foram decrescentes. Dependendo das condições do meio em fermentação, o ciclo da Saccharomyces cerevisiae é muito rápido, quando comparado com o de outros microrganismos, podendo alcançar a fase exponencial em 24 horas. Segundo a mesma autora o aumento proteico foi de 3,5 vezes; obtendo-se como valor máximo $7,92 \%$ de proteína bruta (inicial de 2,26\%). Isso se deve ao alto teor de proteínas e elevada velocidade de crescimento, que estes microrganismos possuem, o que leva a uma rápida produção de biomassa, sendo que esta pode ser contínua e independe das condições do ambiente. (Bekatorou et al., 2006; Kurzman \& Fell, 1998).

Mesmo trabalhando em ampla faixa de $\mathrm{pH}$, as leveduras obtêm melhores resultados quando usada para fermentações, na faixa entre 4,0 e 4,5. $\mathrm{O} \mathrm{pH}$ influencia as fermentações industriais de forma acentuada; pois interfere na contaminação bacteriana, no seu efeito sobre o crescimento das leveduras, sobre as taxas de fermentação e de formação de produtos (Vasconcelos, 2010).

Campos et al. (2005) utilizando bagaço do pedúnculo de caju e Saccharomyces cerevisiae obtiveram um ganho proteico após 28 horas de fermentação de 3 vezes quando comparado ao valor inicial, utilizando $12 \%$ de concentração de levedura. Em estudos anteriores (Campos et al., 2003), quando utilizaram maior concentração do inoculo (16\%), obteve como melhor desempenho, sendo o ganho protéico de 2,5 vezes, valor este também obtido no experimento 8 após $24 \mathrm{hs}$.

Segundo Villas Bôas \& Esposito (2000), a biomassa microbiana, considerada como um concentrado protéico natural contém proteínas completas, com todos os aminoácidos essenciais.

Albuquerque et al. (2003) desenvolveu trabalho para aumento protéico do bagaço de maçã, através da fermentação no estado sólido (FES), onde foi utilizado fungo Rhizopus oligosporus. Dessa forma, avaliou-se a influência de fontes de nitrogênio (ureia e sulfato de amônio) e de soluções tampão (fosfato e ácido cítrico), assim como de suas concentrações, sobre a produção de biomassa. Obtiveram enriquecimento protéico mais significativo, quando usou tampão fosfato $(0,30 \mathrm{M})$, suplementado com ureia a 5\%, que proporcionaram aumento de mais de 5 vezes no teor de proteína do bagaço, que inicialmente apresentava concentração de $5,93 \%$ de proteína solúvel e, após o tratamento, chegou a 30,75\%. Os acréscimos citados foram inferiores aos obtidos nesta série de experimentos.

Estudos anteriores realizados por Shojaosadati et al. (1999), com a finalidade de avaliação do enriquecimento protéico de resíduos em fermentação em estado sólido, de polpa de beterraba, farelo de trigo e resíduo cítrico (proveniente do processamento de limão e laranja), utilizando pra bioconversão o fungo Neurosporas itophila obtiveram resultados positivos, para polpa de beterraba obtiveram enriquecimento protéico de 2,0 vezes, no farelo de trigo houve aumento no teor de proteína de 2,5 vezes e para resíduo cítrico, acréscimo de 3,0 vezes.

A utilização de biomassa de fungos pode aumentar o teor proteico de resíduos agroindustriais, diminuindo os custos na produção animal. Em estudos para melhoramento da qualidade nutricional da silagem com resíduos 
agroindustriais, Pontes (2009) evidencia aumento protéico de 2 a $5 \%$ de proteína bruta no bagaço do caju. Muniz (2009) quando utilizou para enriquecimento protéico do resíduo da vagem de algaroba, a concentração de levedura (Saccharomyces cerevisiae) a $4 \%$ na temperatura de $35^{\circ} \mathrm{C}$; obteve resultado atingindo o maior crescimento protéico no tempo de $72 \mathrm{~h}$, tendo valores de 14,1, 14,3 e 15,7\% respectivamente (acrescentado aproximadamente de 2,0 vezes). Franco et al. (2010) utilizando Aspergillus niger e resíduos de em torno Seriguela que no início da fermentação tinham 7,6\% de Proteína Bruta, após 168 horas de fermentação obtiveram 11,4\% (aumento de 1,4 vezes).

Em experimentos anteriores de Silva et al. (2002), observou-se que ao fornecerem dietas com 14 e $17 \%$ de PB na MS, para novilhos Nelore, na fase de recria, observaram que o consumo de MS aumentou com o incremento de $\mathrm{PB}$ na dieta.

\section{Conclusão}

O tratamento químico de volumosos de baixa digestibilidade mostra-se viável, uma vez que diminui a fração fibrosa dos vegetais. É necessário maiores estudos em relação ao desempenho de animais alimentados com volumosos tratados quimicamente, visando à viabilidade dos mesmos.

O tratamento biológico proporciona um considerável ganho proteico em biomassas, devendo este ser alvo de maiores estudos para proporcionar uma maior viabilidade no tratamento de vegetais, bem como resultados no desempenho animal.

\section{Referências Bibliográficas}

Akin, D. E. Borneman, W. S. \& Lyon, C. E. (1992). Degradation of leaf blades and stems by monocentric and polycentric isolates of ruminal fungi. Animal Feed Science and Technology, 205-221.

Albuquerque, (2003). P.M. Estudo da produção de proteína microbiana a partir do bagaço de maçã, Tese, Universidade Federal de Santa Catarina, Florianópolis - SC.

Bauchop, T. \& Mountfort, D. O. (1981). Cellulose fermentation by a rumen anaerobic fungus in both the presence and absence of rumen ethanogens. Applied and Environmental Microbiology, 42, 103- 110.
Bekatorou, A., Psarianos, C. \& Koutinas, A. A. (2006). Production of food grade yeasts. Food Technology Biotechnology, 44, 407-415.

Berger, L.L., Fahey Jr., G.C. \& Bourquim, L.O (1994). Modification of forage quality after harvest. In: Fahey Jr. G.C. (Ed.). Forage quality, evaluation e utilization. Madison: American Society of Agronomy. p.922-966.

Bertipaglia, L.M.A., De Luca, S., Melo, G.M.P. \& Reis, R.A. (2005). Avaliação de fontes de urease na amonização de fenos de Brachiaria brizantha com dois teores de umidade. Revista Brasileira de Zootecnia, 34, 378-386.

Borneman, W.S., Akin, D.E. \& Ljungdahl, L.G. (1989). Fermentation products and plant cell wall-degrading enzymes produced by monocentric and polycentric anaerobic ruminal fungi. Applied and Environmental Microbiology. 55, 1066- 1073,.

Buettner, M.R., Lechtenberg, V.L., Hendrix, K.S. \& Hertel, J.M. (1982). Composition and digestion of ammoniated tall fescue (Festca arundinacea Schreb.) hay. Journal of Animal Science, 54, 173-178,

Butolo, J.E. (2001). Leveduras vivas e termolizadas na alimentação animal. In: Simpósio Sobre Ingredientes Alternativos $\mathrm{Na}$ Alimentação Animal, 191-198,.

Campos, A. R. N. (2003). Enriquecimento proteico do bagaço do pedúnculo de caju (Anarcadium occidentale L.) por fermentação semi-sólida. Campina Grande, Paraíba, 87p. (Dissertação) - Universidade Federal de Campina Grande.

Campos,, A. R. N., Santana, R. A. C., Dantas, J. P., Oliveira, S. C. \& Silva, F. L. H. (2005). Enriquecimento protéico do bagaço do pendúnculo de caju por cultivo semi-sólido, Revista de Biologia e Ciências da Terra, 5, 50-54.

Carvalho, G. G. P. (2008). Cana-de-açúcar tratada com óxido de cálcio em dietas para ovinos, caprinos, novilhas e vacas em lactação. Tese. Universidade Federal de Viçosa..

Fernandes, L.O., Reis, R.A., Rodrigues, L.R.A., Ledic, I.L. \& Manzan, R.J. (2002). Qualidade do feno de Brachiaria decumbens Stapf. submetido ao tratamento com amônia anidra ou uréia. Revista Brasileira de Zootecnia, 31, 1325-1332. 
Franco, M., Santos, T.C., Gomes, P.P. \& Abreu Filho, G. (2010). Enriquecimento protéico dos resíduos sólidos do processamento de frutas. Enciclopédia Biosfera, 6, 11.

Freitas, D., Coan, R.M., Reis, R.A., Pereira, J.R.A. \& Panizzi, R.C. (2002). Avaliação de fontes de amônia para conservação do feno de alfafa (Medicago sativa L.) armazenado com alta umidade. Revista Brasileira de Zootecnia, $31,866-874$.

Furusho-Garcia, I. F., Perez, J. R. O., Teixeira, J. C. \& Barbosa, C. M. P. (2000). Desempenho de cordeiros Texel x Bergamácia, Texel $\mathrm{x}$ Santa Inês e Santa Inês puros, terminados em confinamento, alimentados com casca de café como parte da dieta. Revista Brasileira de Zootecnia, 29, 564-572.

Garcia, R. \& Pires, A.J.V. (1998). Tratamento de volumosos de baixa qualidade para utilizaçãona alimentação de ruminantes. In: Congresso Nacional dos Estudantes de Zootecnia, Viçosa, MG. Anais... Viçosa, MG: Associação Mineira dos Estudantes de Zootecnia, 33-61.

Joblin, K. N., Matsui, H. Naylor, G.E. \& Ushida, K. (2002). Degradation of fresh ryegrass by methanogenic co-cultures of ruminal fungi grown in the presence or absence of fibrobacter succinogenes. Currents Microbiology, 45, 46-53.

Kurzman, C. P. \& Fell, J. W. (1998). The yeasts: a taxonomic study. 4. ed. New York: Elsevier, 1074.

Li, J. \& Heath, I.B. (1999). Cchytridiomycetous gut fungi, of overlooked contributors to herbivore digestion. Canadian Journal of Microbiology, 39, 1003-1013.

Li, X. L., Chen, H. \& Ljungdahl, L. G. (1997). Monocentric and polycentric anaerobic fungi produce structurally related cellulases and xylanases. Applied Environement Microbiology, 63, 628-635.

Ljungdahl, L. G. Chou, C.F. \& Chen, H. (1999). The cellulase/hemicellulase system of the anaerobic fungus Orpinomyces and aspects of further cellulase research. In: Ohmiya, K. et al. (Ed.). Genetic, biochemistry and ecology of cellulose degradation. Tokyo: Uni Publishers, p.495-506.

Mallmann, G.M., Patino, H.O., Silveira, A,L.F., Medeiros, F.S. \& Knorr, M. (2006). Consumo e digestibilidade de feno de baixa qualidade suplementado com nitrogênio não protéico em bovinos. Pesquisa Agropecuária Brasileira, 41, 331-337.

Muniz, M.B. (2009). Processamento das vagens de algaroba (Prosopolis juliflora) para produção de bioprodutos; Tese, Universidade Federal de Campina Grande.

Neiva, J. N. M., Garcia, R., Valadares Filho, S. C., Pereira, O. G. Aureliano Pires, J. V.\& Silva, H. A. (1998) Desempenho de bovinos de corte alimentados com dietas à base de silagens e rolão de milho amonizados. Revista Brasileira de Zootecnia, 27, 466-473.

Oliveira Jr., R.C., Pires, A. V. \& Fernandes, J. J. R., Susin, I., Santos, F.A.P., Filho, F.A.P. (2004). Avaliação de marcadores para estimar a digestibilidade dos nutrientes em novilhos nelore alimentados com dietas contendo alto teor de concentrado e fontes nitrogenadas. Revista Brasileira de Zootecnia, 33, 749-758.

Oliveira, E. G. (2007). Métodos físico-químicos; Apostila adotada em aula prática; Universidade Federal de Alagoas.

Pereira, J.R.A., Ezequiel, J.M.B., Reis, R.A., Rodrigues, L. R. A. \& Bonjardim, S.R. (1993). Efeitos da amonização sobre o valor nutritivo do feno de capim braquiária. Pesquisa Agropecuária Brasileira, 28, 14511455.

Pinheiro, R.S.B., Sobrinho, A.G.S., Siqueira, G. R. \& Andrade, E. N. (2009). Amonização do resíduo da produção de sementes de forragem no desempenho e biometria de cordeiros. Ciência Animal Brasileira, 10, 711-720.

Pires, A.J.V., R. Garcia, A.L., Souza, F.F., Silva, C.M. Veloso, G.C., Cardoso, T.N., Oliveira E. \& Silva. P.A. (2003). Avaliação do consumo de silagens de sorgo tratadas com amônia anidra, e, ou, sulfeto de sódio na alimentação de novilhas 3/4 Indubrazil/Holandês. Revista Brasileira de Zootecnia, 32, 1525-1531.

Pires, A.J.V., Garcia, R., Valadares Filho, S.C., Pereira, G. O., Cecon, P. R., Silva, F. F., Silva, P. A. \& Veloso, C. M. (2004). Novilhas alimentadas com bagaço de cana-de-açúcar tratado com amônia anidra e, ou, sulfeto de sódio. Revista Brasileira de Zootecnia, 33, 1078-1085.

Pontes, C. R. (2009). Enriquecimento protéico do bagaço de caju através de fermentação semi- 
sólida utilizando Aspergillus Níger, Tese (Mestrado) - Universidade Federal do Ceará, Fortaleza.

Reis, R.A., Rodrigues, L.R.A., Pereira, J.R.A. \& Ruggieri, A.C. (2001). Composição química e digestibilidade de fenos tratados com amônia anidra ou uréia Revista Brasileira de Zootecnia, 30, 666-673.

Rodrigues, A.A. \& Souza, F.H.D. (2006). Perspectivas de utilização da palhada residual da produção de sementes capim para alimentação de ruminantes. In: Souza, F.H.D., Pott, E.B., Primavesi, O., Bernardi, A.C.C., Rodrigues, A.A. (Eds). Usos alternativos da palhada residual da produção de sementes para pastagens. São Carlos: EMBRAPA, 6587.

Rosa, B., Reis, R.A., Panizzi, R.C., Mesquita, A. J. \& Jobim, C. C. (1998b). Preservação do feno de Brachiaria decumbens Stapf cv. Basilisk submetido a tratamento com amônia anidra ou uréia. Revista Brasileira de Zootecnia, 27, 691-694.

Rosa, B. \& Fadel, R. (2001). Uso de amônia anidra e de uréia para melhorar o valor alimentício de forragens conservadas. In: Simpósio sobre produção e utilização de forragens conservadas. Maringá. Anais... Maringá: UEM/CCA/DZO.41-63.

Roth, M.T.P., Resende, F.D., Reis, R.A., Siqueira, G.R., Faria, M.H. \& Berchielli, T.T. (2008). Performance and carcass characteristics of beef cattle fed with ammoniated marandugrass hay. Revista Brasileira de Zootecnia., v.38, n.9, p.18471855.

Roth, M.T.P., Reis, R.A., Resende, F.D., Siqueira, G. R, Pires, A. J. V. \& Bertipaglia, L.M.A. (2009). Tratamento químico do resíduo de pós-colheita de sementes da Brachiaria brizantha cv. Marandu com diferentes teores de umidades. Revista Brasileira de Zootecnia.

Selinger, L. B.,Forsberg, C. W. \& Cheng, K.-J. (1996). The rumen: a unique source of enzymes for enhancing livestock production. Anaerobe, 2, 263-284.

Shojaosadati, S. A., Faraidouni, R. MadadiNouei, A. \& Mohamadpour, I. Protein enrichment of lignocellulosic substrates by solid state fermentation using Neuros- porasitophila. Resources, Conservation and Recycling, 27:73-87,1999.

Silva, F.F., Valadares Filho, S.C., Ítavo, L.C., Veloso, C. M., Paulino, M. F. Cecon, P. R., Silva, P. A. \& Galvão, R. M. (2002). Desempenho Produtivo de Novilhos Nelore, na Recria e na Engorda, Recebendo Dietas com Diferentes Níveis de Concentrado e Proteína. Revista Brasileira de Zootecnia,31, 492-502.

Sniffen, C.J., O'connor, J.D. \& Van Soest, P.J. (1992). A net carbohydrate and protein system for evaluation cattle diets. II. Carbohydrate and protein availability. Journal of Animal Science, 70, 3562-3577.

Souza, A.L., Garcia, R., Pereira, O.G., Cecon, P.R., Valadares Filho, S.C. \& Paulino, M.F. (2001). Composição químico-bromatológica da casca de café tratada com amônia anidra e sulfeto de sódio. Revista Brasileira de Zootecnia, 30, 983-991.

Souza, F. H. D. \& Silveira, G. C. (2006). A partilha residual da produção de sementes de capins tropicais no Brasil. In: Souza, F. H. D. De., Pott, E. B., Primavesi, O., Bernadi, A. C. C., Rodrigues, A. A. (Ed.). Usos alternativos de palhada residual da produção de sementes para pastagens. São Carlos: EMBRAPA Pecuária Sudeste, 13-28.

Sundstol, F. \& Coxworth, E.M. 1984. Ammonia treatment. In: Sundstol, F., Owen, E. (Eds.) Straw And Others fibrous by-products as feed. Elsevier Press. 196-247.

Tortora, G.J., Funke, B.R. \& Case, C.L. (2002). Microbiology. 6 ed. Califórnia: Art Méd.

Trinci, A. P. J., Davies, R., Gull1, K., Lawrence, M. I., Nielsen, B. B., Rickers, A. \& M. K. Theodorou. (1994). Anaerobic fungi in herbivorous animals. Mycology Research, 98, 129-152.

Vasconcelos, J.N. (2010) Fermentações Etanólicas, In: Cana-de-açúcar- Bioenergia.

Vilela, E.S.D., Sgarbieri, V.C. \& Alvim, I.D. (2000). Valor nutritivo da biomassa de células íntegras, do autolisado e do extrato de levedura originária de cervejaria. Revista de Nutrição, 13, 127-134.

Villas Bôas, S. G. \& Esposito, E. (2000). Bioconversão do bagaço de maçã: enriquecimento nutricional utilizando fungos 
para produção de um alimento alternativo de alto valor agregado. Biotecnologia, Ciência \& Desenvolvimento, 14, 38-42,.

Williams, P.E.V., Innes, G.M. \& Brewer, A. (1984). Ammonia treatment of straw via the hydrlysis of urea: II. Additions of soya bean (urease), sodium hydroxide and molasses; efects on the digestibility of urea-treated straw. Animal Feed Science and Technology, $11,115-124$.

Ximenes E.A. (2003). Fungos Anaeróbicos. Revista Ciências Médicas e Biologia, 2, 269275.

Zanine, A.M., Santos, E.M., Ferreira, D.J. \& Pereira, O.G. (2007). Efeito da amonização sobre o desenvolvimento de mofos e leveduras e valor nutricional do bagaço de canade-açúcar. Revista de Biologia e Ciências da Terra, 6,222-231.

Recebido em Outubro 1, 2015

Aceito em Novembro 30, 2015

License information: This is an open-access article distributed under the terms of the Creative Commons Attribution License, which permits unrestricted use, distribution, and reproduction in any medium, provided the original work is properly cited. 